\title{
Kirchliche Filmpreise 2005
}

Aufgeführt ist im Folgenden eine Auswahl der Preise von Jurys der kirchlichen Filmorganisationen SIGNIS (katholisch) und INTERFILM (evangelisch), die im Jahre 2005 auf wichtigen internationalen Filmfestivals vergeben wurden.

\section{Internationale Filmfestspiele Berlin (10. bis 20.Dezember 2005)}

Die Ökumenische Jury vergibt in Berlin Preise in den Programmsektionen Internationaler Wettbewerb, Panorama und Internationales Forum des Jungen Films.

\section{Internationaler Wettbewerb}

Preis der Ökumenischen Jury:

\section{Sophie Scholl - Die letzten Tage}

Deutschland 2005

Regie: Marc Rothemund

Begründung:

Basierend auf einem Drehbuch, das in ausgezeichneter Weise neue historische Quellen einarbeitet, zeigt Marc Rothemunds Film mit minimalistischer Ästhetik und konsequenter Erzählstrategie die letzten sechs Tage im Leben der Widerstandskämpferin Sophie Scholl. Das Psycho-Duell der glänzenden Schauspieler vermittelt das humane aufgeklärte Denken der jungen Studentin, das im christlichen Glauben wurzelt. Der Film verweist auf einen dialogfähigen, christlichen Standpunkt, der in konsequenter Zivilcourage und im Widerstand gegen totalitäre Denk- und Machtstrukturen seinen Ausdruck findet.

\section{Programmsektion Panorama}

Preis der Ökumenischen Jury:

Va, vis et deviens (Geh und lebe)

Frankreich/Israel 2004

Regie: Radu Mihaileanu

Begründung:

Ein äthiopischer Junge mit christlichen Wurzeln verläßt das hungergeplagte Flüchtlingslager im Sudan und erreicht Israel als Land "voll Milch und Honig". Hier wächst er versteckt als Jude auf und findet sich zuneh- 
mend mit seiner gespaltenen Identität zurecht. Radu Mihaileanus Film zeigt Verständnis für die aktuelle Vielfalt von Migrationswegen und ermutigt zum Weiterleben mit wechselnden ethnischen und religiösen Bindungen: eine lohnenswerte Reise zu spirituellem Wachstum, zum Leben und Werden.

Programmsektion Internationales Forum des jungen Films Preis der Ökumenischen Jury:

\section{Ratziti Lihiyot Gibor (On the Objection Front)}

Israel 2004

Regie: Shiri Tsur

Begründung:

Der Film erzählt die persönlichen Entwicklungen von sechs israelischen Soldaten, die nach ihrer langjährigen Militärzeit ihren jährlichen Reservedienst in den besetzten Gebieten verweigern. Ihre Zeugnisse vermitteln, wie die Gründungsvision der jüdischen Tradition persönliches Umdenken und soziale Veränderungen in Gang setzen kann.

\section{Internationale Kurzfilmtage Oberhausen (5. bis 10.Mai 2005)}

Preis der Ökumenischen Jury:

City Paradise (Stadtparadies)

Großbritannien 2004

Regie: Gaëlle Denis

Begründung:

Der Film erzählt auf originelle und anrührende Weise die Geschichte einer wunderbaren Verwandlung. Zusammen mit der Protagonistin tauchen wir ein in eine Atmosphäre der Leichtigkeit, die das Fremdsein überwindet. Die Regisseurin beweist, wie amüsant und unterhaltsam die Auseinandersetzung mit existenziellen Fragen geschehen kann.

Lobende Erwähnung:

Border (Grenze)

Großbritannien/Frankreich 2005

Regie: Laura Waddington

Begründung:

Abseits der herkömmlichen Berichterstattung konfrontiert uns die Regisseurin mit ungewohnten Bildern einer politischen Tragödie. Sie verleiht, selbst Grenzgängerin zwischen Sichtbarem und Unsichtbarem, den konturlosen Gesichtern ein Profil - Menschen im Dunkeln. 


\section{Internationale Filmfestspiele Cannes (11. bis 22. Mai 2005)}

Preis der Ökumenischen Jury:

\section{Caché}

Frankreich/Österreich/Deutschland/Italien 2005

Regie: Michael Haneke

Begründung:

Das intime Leben eines Fernsehmoderators wird durch einen anonymen Beobachter gefilmt. Die entsprechenden Videocassetten, die ihm in regelmässigen Abständen zugestellt werden, beunruhigen und verwirren ihn, weil sie Kindheitserinnerungen wecken und Bezüge zur Tagesaktualität herstellen. In einem strengen Stil evoziert der Filmemacher die Komplexität der Verantwortung des Menschen gegenüber seiner Vergangenheit und der Geschichte.

Lobende Erwähnung an einen Film aus der Sektion "Un Certain Regard “: Delwende

Burkina Faso/Frankreich/Schweiz 2005

Regie: S. Pierre Yameogo

Begrïndung:

Mit dem Lob wird die hoffnungsvolle Geschichte einer mutigen jungen Frau ausgezeichnet, die sich der repressiven Männerherrschaft ihres afrikanischen Dorfes widersetzt und gewissen abergläubischen Bräuchen Wahrheit und Solidarität entgegenstellt.

\section{Internationales Filmfestival Locarno (3. bis 13. August 2005)}

Preis der Ökumenischen Jury:

La Neuvaine (Die Novene)

Kanada 2005

Regie: Bernard Émond

Begründung:

Während viele religiöse Filme an ihren Bekehrungsbemühungen oder an einer befremdlichen Frömmigkeit scheitern, gelingt es "La Neuvaine", Glaubensgewissheit zu respektieren und gleichzeitig die Schwierigkeiten anzuerkennen, in einer säkularen Welt und im Schatten gewaltsamer Tragödien an Gott zu glauben Ein junger Mann, der für seine sterbende Großmutter einen neuntägigen Gebetsritus vollzieht, trifft auf eine durch das Erlebnis sinniloser Gewalt traumatisierte Ärztin. Ihre Begegnung führt nicht $\mathrm{zu}$ Wundern oder einer Bekehrung, sondern zu Güte und erneuerter Hoffnung. 
Lobende Erwähnung:

Fratricide - Brudermord

Deutschland/Frankreich/Luxemburg 2005

Regie: Yilmaz Arslan

Begründung:

"Fratricide“ fordert zur Auseinandersetzung mit dem drängenden europäischen Flüchtlingsproblem heraus. Der Film spielt unter Kurden in Deutschland. Yilmaz Arslan verbindet die komplexe Geschichte zweier Brüder sowohl mit Szenen physischer Gewalt als auch mit dem anrührenden Bild freundschaftlicher Fürsorge. Sein Film ist eine Anklage gegen Rassismus und Ignoranz, aber auch ein Plädoyer für umfassende Menschlichkeit und Würde.

\section{Internationales Filmfestival Venedig (31. August bis 10. September 2005)}

Preis der internationalen katholischen Medienorganisation SIGNIS:

Mary

Italien/Frankreich 2005

Regie: Abel Ferrara

Begründung:

Der Film handelt von einer Schauspielerin, einem Regisseur und einem TV-Anchorman, von denen jeder seine eigene persönliche Krise durchlebt. Unkonventionell im filmischen Stil, zeigt er die Ängste und Gefah ren in unserer heutigen Welt, die Manipulation der Wahrheit durch die Medien, den exzessiven religiösen Fundamentalismus und gleichzeitig das Verlangen nach Spiritualität in der Menschheit.

\section{Internationales Leipziger Festival für Dokumentar- und Animationsfilm (3. bis 9. Oktober 2005)}

Preis der Ökumenischen Jury:

L'Avenir (Die Zukunft)

Spanien 2005

Regie: Claudio Zulian

Begründung:

Wie eine französische Kleinstadt durch den Verlust der ortsansässigen Arbeit stirbt, die Menschen aber weiterleben, zeigt der Schwarzweißfilm von Claudio Zulian. Streng komponiert in Bild und Ton verweist der kurze Film auf eine gegenwärtige gesellschaftspolitische Entwicklung. Vergangenheit, Gegenwart und Zukunft von Arbeit, innovativ erzählt, überzeugt die ökumenische Jury. 


\section{Festival des osteuropäischen Films in Cottbus (8. bis 12. November 2005)}

Preis der Ökumenischen Jury

Odgrobadogroba (Gravehopping/ Von Grab zu Grab)

Slowenien/Kroatien 2005

Regie: Jan Cvitkovic

Begründung:

Am Ende bleibt Pero stumm: Der Tod, mit dem er als Grabredner sein Geld verdient, wird im Lauf des Films zu einer unaussprechlichen Erfahrung. Mit viel Humor und langen, ausdrucksstarken Einstellungen entfaltet Jan Cvitkovic ein Netz von Beziehungen, die alle um das Thema Liebe und Tod kreisen. Ein slowenisches Dorf wird zum Mikrokosmos unter südlicher Sonne, in dem sich die komischen und abgründigen Aspekte der Vergänglichkeit miteinander verbinden. Verschiedene Modelle werden durchgespielt, das Rätsel „Tod“ zu erklären. Die Möglichkeit einer Erlösung schimmert auf.

\section{Internationales Filmfestival Mannheim-Heidelberg (17. bis 26. November 2005)}

Preis der Ökumenischen Jury:

Pavee Lackeen (Wohnwagenleben)

Irland 2005

Regie: Perry Ogden

Begründung:

Der Film beschreibt authentisch die Lebenssituation einer kinderreichen irischen Familie, die am Stadtrand von Dublin in Wohnwagen lebt. Dabei gelingt es dem Regisseur, ohne falsche Hoffnung zu wecken, den Mut und die Lebenskraft seiner jungen Protagonistin zu zeigen.

Lobende Erwähnung:

Ryna (Ryna, das Mädchen)

Schweiz/Rumänien 2005

Regie: Ruxandra Zenide

Begrïndung:

Der Film über die Suche eines jungen Mädchens nach der eigenen Identität besticht durch seine einfühlsame und genaue Beobachtung der Seelenlandschaft'seiner Protagonistin in ihrem Umfeld. 